\title{
What is research in mathematics education, and what are its results?
}

\author{
Anna Sierpinska, Concordia University \\ Jeremy Kilpatrick, University of Georgia \\ Nicolas Balacheff, Didatech, IMAG \& Université Joseph Fourier \\ A. Geoffrey Howson, University of Southampton \\ Anna Sfard, Science Teaching Center, Hebrew University \\ Heinz Steinbring, IDM, Universität Bielefeld
}

As mathematics education has become better established as a domain of scientific research (if not as a scientific discipline), exactly what this research is and what its results are have become less clear. The history of the past three International Congresses on Mathematical Education demonstrates the need for greater clarity. At the Budapest congress in 1988, in particular, there was a general feeling that mathematics educators from different parts of the world, countries, or even areas of the same country often talk past one another. There seems to be a lack of consensus on what it means to be a mathematics educator. Standards of scientific quality and the criteria for accepting a paper vary considerably among the more than 250 journals on mathematics education published throughout the world.

The community of people concerned with research in mathematics education is increasingly divided into specialized groups and cliques that are not always tolerant of each other. Besides mutual understanding within the community, however, there is also a need to explain the domain to representatives of other scientific communities, among which the community of mathematicians seems to be the most important.

Many people want to develop research in mathematics education within the academic community of mathematicians. This implies both the explanation of the research's purpose on a social ground (Is there any need to develop such 
research?) and its relevance within the narrow academic world. Questions arise as to scientific standards, dissertations, publications, congresses, the employment of young academics in the field, and the connection between this research and the research done in other fields. Thus we need an inner identification of the research domain of mathematics education, as well as an outer vision from the perspective of other domains.

One external domain, for example, is sociology. How is mathematics education organized and institutionalized? Where is research on mathematics education conducted? Where are dissertations on mathematics education defended? Is a mathematics educator with a doctorate from a college of education and employed by a mathematics department accepted as a full member of the community of mathematicians? Are mathematics educators viewed as a part of the mathematics community? Similar questions arise when research in mathematics education is surveyed from other domains, including history, philosophy, anthropology, and psychology. In this article, we pose a number of questions about research in mathematics education that arise from inside and outside the domain.

\section{What is the specific object of study in mathematics education?}

The object of study (der Gegenstand) in mathematics education might be, for example, the teaching of mathematics; the learning of mathematics; teaching and learning situations; the relations between teaching, learning, and mathematical knowledge; the reality of mathematics classes; societal views of mathematics and its teaching; or the system of education itself.

If a mathematics educator studies mathematics, is it the same object for him or her as it is for a mathematicians who studies mathematics? What is mathematics as a subject matter? What is "elementary mathematics"? Analogous question could be asked concerning the learner of mathematics as an object of study. Is it the same object for a mathematics educator as it is for a psychologist or a pedagogue? Is the mathematics class or the process of learning in the school viewed in the same way by a mathematics educator and a sociologist, anthropologist, or ethnographer? Are questions of knowledge acquisition viewed the same way by a mathematics educator and an epistemologist? 


\section{What are the aims of research in mathematics education?}

One might think of two kinds of aims: pragmatic aims more fundamental scientific aims. Among the more pragmatic aims would be the improvement of teaching practice as well as of students' understanding and performance. The chief scientific aim might be develop mathematics education as a recognized field of research.

What might the structure of such field be? Would it make sense to structure it along the lines of mathematical subject matter (e. g., the didactics of algebra or the didactics of geometry), of various theories or approaches to the teaching and learning of mathematics, or of specific topics or problématiques, that is, specific research questions related to a theoretical framework (research on classroom interaction and communication, research on students' understanding of concept, etc.)?

Both kinds of aims seem to assume that it is possible to develop some kind of professional knowledge, whether that of a mathematics teacher, a mathematics educator, or a research in mathematics education. The question arises, however, whether such professional knowledge can exist. Is it possible to provide a teacher, say, with a body of knowledge that would, so to say inevitably, ensure the success of his or her teaching? In other words, is teaching a profession (un métier) or an art?

On what does successful teaching depend? Are there methods of teaching so sure, so objective, that they would work no matter who the teacher and students were? Are there methods of teaching that are teacher-proof and methods of learning that are student-proof? If not, is there anything like objective fundamental knowledge for a researcher in mathematics education - something that any researcher could build on, something accepted and ageed on by all? Or will the mathematics education community inevitably be divided by what is considered to belong to this fundamental knowledge?

Many mature fields of scientific knowledge have become specialized into narrow subfields. Is this the fate of mathematics education as well? Or rather, in view of the interdisciplinary nature of mathematics education, must every researcher necessarily be a humanist, knowing something of all domains and problems in mathematics education? 


\section{What are the specific research questions or problématiques of research in mathematics education?}

Mathematics education lies at the crossroads of many well-established scientific fields such as mathematics, psychology, pedagogy, sociology, epistemology, cognitive science, semiotics, and economics, and it may be concerned with problems imported from these fields. But mathematics education certainly has its own specific problématiques that cannot be viewed as particular cases or applications of those from other fields. One question to be addressed is that of identifying and relating to each other the various problématiques specific to mathematics education.

There are two distinct types of questions in mathematics education: those that stem directly or almost directly from the practice of teaching and those generated more by research. For example, the question of identifying students' difficulties in learning a specific piece of mathematics belongs to the first kind. But questions of classifying difficulties, seeing how widespread a difficulty is, locating its sources, or constructing a theoretical framework to analyze it belong among the research-generated questions. A difficulty may remain unnoticed or poorly understood without an effort to answer questions of latter type, that is, without more fundamental research on students' understanding of a topic. Is it, therefore, possible to separate so-called practical problems from so-called research-generated problems?

Is it possible to admit the existence of two separated types of knowledge: the theoretical knowledge for scientific community of researchers and the practical knowledge useful to reflect on the nature of these two types of knowledge, on relations between them, and on whether it would be possible to have a unified body of knowledge encompassing them both.

\section{What are the results of research in mathematics education?}

Any result is relative to a problématique, to the theoretical framework on which it is directly or indirectly based, and to the methodology through which it was obtain. This relativity of results, though commonplace in science, is often forgotten.

Two types of findings can be distinguished in mathematics education: those based on long-term observation and experience and those founded on specially mounted studies. Are the former less scientific than latter? In the seventeenth 
century, Spinoza set out three levels of understanding of the rule of three (which, incidentally, can be viewed as an elaboration of the instrumentalrelation model of Skemp and Mellin-Olsen, expounded over three centuries later). This, like the well-known levels of van Hieles, was based on observation and experience. In contrast, for example, the Concepts in Secondary Mathematics and Science (CSMS) project used specially mounted classroom studies to develop and investigate similar hierarchies of understanding. Do we rule out the work of Spinoza as research in mathematics education? If we do, then we lose much valuable knowledge, especially that resulting from curriculum development. If we do not, then it becomes difficult to find a workable definition of research in mathematics education.

If we attempt to contrast hierarchies - say those obtained by the van Hieles and the CSMS group, we observe that (a) the hierarchies were obtained in different ways, and (b) the researchers may not have been asking the same kind of question. What were these questions? How valid are the answers they provide? How is it possible to relate them?

Most people would probably agree that making empirical investigations is research. But is doing practical things research? Is thinking research? Can these activities be separated? Can a result be obtained without thinking and the doing of practical things? Should mathematics education be considered a science? Perhaps it is a vast domain of thought, research, and practice. What qualities a domain of activity as scientific is the kind of validation and justification methods it uses. Proofs and experiments are considered scientific. But there are thoughts not validated in either of these ways that are valuable because they are filled with meaning.

Can we identify some categories of results? One category might be economizers of thought. Any facts, laws, methods, procedures, or theories that are general enough to direct our experience and predict its results will give us increased power over our teaching and learning. Another category might be demolishers of illusions. Results that undermine our beliefs and assumptions are always valuable contributions to the field. A third category might be energizers of practice. Teachers welcome research that helps them understand what they teach and provides them with ideas for teaching. The development of teaching materials, activities, and challenging problems belongs to this category. Other categories of results might emerge from epistemological, methodological, historical, and philosophical studies. 


\section{What criteria should be used to evaluate the results of research in mathematics education?}

How do we assess the validity of research findings? How do we assess their worth? Should we use the criterion of relevance? What about objectivity? Or originality? Should we consider the influence research has had on the practice of teaching?

The first problem is to clarify the meaning of terms such as truth, validity, and relevance in the context of mathematics education. A related issue is the question of what is knowledge as such. This is an even more fundamental question than that of validation. If we knew what kind of knowledge mathematics education aims at, we would be better equipped for answering the question of methods of validation.

It is also useful to understand the ways in which research are used. How have the results of research in mathematics education been applied? How do teachers or policy makers use the research? By clarifying the uses to which research is put, we may be able to develop better criteria for assessing its validity.

We in mathematics education have not been very reflective about the growing body of research we have been producing. The question posed above, and others like them, deserve more thorough consideration than they have received to date. They appear to require extensive thought and discussion if the field of mathematics education is become more coherent.

Anna Sierpinska, Concordia University, Montréal, CANADÁ. Jeremy Kilpatrick, 105 Aderhold Hall, Athens, GA 30602-7124, EUA. Nicolas Balacheff, IMAG, BP 53X, 38041 GRENOBLE cedex, FRANÇA.

A. Geoffrey Howson, University of Southampton. INGLATERRA. Anna Sfard, Science Teaching Center, Hebrew University. ISRAEL. Heinz Steinbring, Institut für Didaktik der Mathematik, Universität Bielefeld, D-4800 Bielefeld 1, ALEMANHA.

Artigo originalmente publicado no Journal for Research in Mathematics Education, 24, 274-278, 1993. 